\title{
Present-climate precipitation and temperature extremes over Spain from a set of high resolution RCMs
}

\author{
Marta Domínguez ${ }^{1, *}$, Raquel Romera ${ }^{1}$, Enrique Sánchez ${ }^{2}$, Lluis Fita ${ }^{3}$, \\ Jesús Fernández ${ }^{3}$, Pedro Jiménez-Guerrero ${ }^{4}$, Juan Pedro Montávez ${ }^{4}$, \\ William David Cabos ${ }^{5}$, Giovanni Liguori ${ }^{5}$, Miguel Ángel Gaertner ${ }^{2}$ \\ ${ }^{1}$ Environmental Sciences Institute, Environmental Science Institute, 45071 Toledo, Spain \\ ${ }^{2}$ Environmental Science Faculty, University of Castilla-La Mancha, 45071 Toledo, Spain \\ ${ }^{3}$ Grupo de Meteorología, Dept. Applied Mathematics and Computer Science, University of Cantabria, 39005 Santander, Spain \\ ${ }^{4}$ Department of Physics, Regional Campus of International Excellence 'Campus Mare Nostrum', University of Murcia, \\ 30100 Murcia, Spain \\ ${ }^{5}$ Department of Physics, Climate Physics Group, University of Alcalá de Henares, 28805 Madrid, Spain
}

\begin{abstract}
In the frame of the Spanish project ESCENA, 5 regional climate model simulations were analyzed in terms of their representation of precipitation and temperature extremes over Spain. The climate complexity of the target domain poses a challenge for the models in terms of their ability to simulate precipitation and temperature extremes. There are important differences in comparison to previous similar studies (such as PRUDENCE and ENSEMBLES European projects): the domain of the present-climate simulations (1990 to 2007) is centered over the Iberian Peninsula (IP), and the simulations are nested in ERA-Interim reanalysis. Two of the models (WRF and MM5) were not part of the ENSEMBLES project. A new high-resolution $\left(0.2^{\circ} \times 0.2^{\circ}\right)$ database (Spain02) of daily temperature and precipitation observations over Spain was used to validate the results. The performance of the models depends on the climatic characteristics of the subregions. Results are better for the northern coastal area of Spain, but for other Atlantic basins there are some biases that cannot be linked to limitations in the representation of very heavy convective events. Several models underestimate the amount of rain for heavy-precipitation days. This aspect has not improved in general in comparison to ENSEMBLES results, despite the differences in setup. In other respects, all models are at a similar level as the best subgroup of ENSEMBLES models. The ESCENA simulations (covering more emissions scenarios and GCMs than ENSEMBLES project) can thus be considered a valuable complement of that European project for impact studies over Spain.
\end{abstract}

KEY WORDS: Climate extremes - Extreme precipitation - Extreme temperatures - Regional climate models $\cdot$ Iberian Peninsula $\cdot$ Heavy precipitation $\cdot$ Droughts $\cdot$ Heat waves

\section{INTRODUCTION}

The analysis of extreme events under the present climate is important in order to assess the reliability of climate change projections, because it is likely that the frequency and intensity of extreme events and the size of affected areas will increase in the future (Sánchez et al. 2011, Field et al. 2012). Beniston et al.
(2007) defines an extreme event as rare, intense and severe. Thus, extreme events are usually analyzed in terms of frequency distribution tails of climate variables, including high percentiles and record-breaking events, known to have caused severe impacts.

A global tendency towards an increased frequency of some extreme events during the 20th century has been found in several studies, but the results show 
large spatial variability (Alexander et al. 2006, Vincent \& Mekis 2006, López-Moreno \& Beniston 2009, Hirschi et al. 2010). The socio-economic impact of extreme temperature is not only related to hot or cold individual days, but also to persistent events like cold and heat waves (Fischer \& Schär 2010). More frequent and intense summer heat waves have been observed at global and European scales (Alexander et al. 2006, Della-Marta et al. 2007, Barriopedro et al. 2011).

To understand the mechanisms behind extreme events in present and future climate, global circulation models (GCMs) and regional climate models (RCMs) have been used. The increased frequency of observed extreme events has been studied at different spatial scales, from global (Frich et al. 2002), to continental (Beniston \& Stephenson 2004, Schär et al. 2004) and down to regional scale (Huth et al. 2000). On this respect, the Intergovernmental Panel on Climate Change (IPCC 2001, 2007) recommended more adequate analyses and regional detail for model projections. At the same time, end-users, such as impact modellers, demand climate data at higher spatial resolution than given by GCMs (Castro et al. 2007). There is, thus, a need for high resolution climate projections. Additionally, model uncertainties are explored by means of multi-model ensembles of simulations. The generation of high-resolution regional climate information through an ensemble of RCM simulations has been the basis for several international projects (e.g. PRUDENCE, ENSEMBLES in Europe, NARCCAP in North America). Currently, such an approach is being extended to most continental regions of the world in the frame of CORDEX project (COordinated Regional climate Downscaling EXperiment; Giorgi et al. 2009). Among other advantages, the estimation of the spatial and temporal distribution of extreme precipitation episodes has been improved using climate models with high resolution (Beniston 2006, Frei et al. 2006, Beniston et al. 2007) compared to those using lower resolutions.

In the Mediterranean region, extreme events have strong impacts on ecosystems, socio-economic activities and agriculture (Vicente-Serrano et al. 2004, Lana et al. 2006, Vicente-Serrano 2006a). Results from RCMs including the Iberian Peninsula (IP) in their domains (Sánchez et al. 2004, 2011, López-Moreno \& Beniston 2009, Herrera et al. 2010) highlight the importance of high spatio-temporal resolution for the study of extreme events over this area. The irregularity of precipitation and the strong seasonal variations in the IP make this region particularly interesting for the study of precipitation and temperature extremes, which caused considerable damage over the last century (García-Herrera et al. 2005, Vicente-Serrano 2006b). Instead of considering the IP as a single region as in previous studies performed in the frame of PRUDENCE and ENSEMBLES European Projects (e.g. Boberg et al. 2009, 2010, Fischer \& Schär 2010, Kjellström et al. 2010), in the present study the analyzed domain has been divided in 6 subregions to take into account the high spatial variability of the IP climate. A correct simulation of present climate is needed to detect changes in key variables that could modify the availability of water resources (MartinVide 2004, López-Moreno \& Beniston 2009).

In previous modelling studies over Europe, RCM simulations were compared with the gridded observational climate database E-OBS (Haylock et al. 2008). E-OBS has been very useful in many analyses of temperature extremes (Fischer et al. 2007, Hirschi et al. 2010). However, due to the high spatial variability of the climate in the IP, the amount of stations underlying E-OBS is insufficient for this region. High resolution climate data (Brunetti et al. 2001, GonzálezHidalgo et al. 2003) and gridded data based on much denser station networks than E-OBS are needed for RCM evaluation studies (Kysely \& Plavcova 2010). Here we use the $0.2^{\circ} \times 0.2^{\circ}$ gridded daily precipitation and temperature dataset Spain02 (see section 2.3), developed for Peninsular Spain (PS) and the Balearic Islands (BA) (Herrera et al. 2012). Spain02 was tested (Herrera et al. 2012) against point observations and compared to E-OBS database. This new database (Spain02) proved to represent better the intensity and spatial variability of several standard extreme climate indices defined by Sillmann \& Roeckner (2008).

The present study analyzes the results for present climate from 5 RCM simulations, focusing on their ability to represent extreme events. The RCM simulations have been performed within the Spanish project ESCENA, and complement and extend ENSEMBLES results (using the same horizontal resolution of $25 \mathrm{~km}$ ) through the use of improved and/or additional RCMs, new GCM/RCM matrix combinations, and a larger set of emission scenarios (A1B, A2 and B1). Results of ESCENA project are publicly available for impact or regional climate studies (http://proyectoescena.uclm. es). An important difference with respect to PRUDENCE and ENSEMBLES is the simulation domain. It is centered over the IP and covers larger parts of the Atlantic Ocean, including the Canary Islands, which were not included in these European projects. Additionally, evaluation model runs are forced by the ERAInterim reanalysis instead of the ERA-40 reanalysis used in ENSEMBLES. We focused this study on PS 
and the BA, where the high-resolution Spain02 database is available.

\section{METHODS AND DATA}

\subsection{Regional climate models}

The RCM ensemble includes 5 different models (PROMES, 2 versions of WRF model, MM5 and REMO). These models have been developed at different institutions. A summary of the physics parameterizations for each of them is shown in Table 1. These models are described in more detail in Jiménez-Guerrero et al. (2013).

The RCM PROMES (Castro et al. 1993, Sánchez et al. 2004) was developed at the Complutense University of Madrid and the University of Castilla-La Mancha (Spain). Several changes have been introduced in PROMES with respect to previous simulations. The most significant changes are the coupling to ORCHIDEE land surface model (Krinner et al. 2005) and the change of radiation parameterization, as explained in Domínguez et al. (2010). The Weather Research and Forecasting (WRF) model is a state-of-theart limited area model developed in collaboration between the National Center for Atmospheric Research (NCAR) and a number of research institutions in the US. In this study we used the Advanced Research WRF core (version 3.1.1; Skamarock et al.
2008), which is the research version of the model. WRF model simulations were run by the Santander Meteorology Group of the University of Cantabria, Spain. The model includes modifications introduced by this group to get averaged and extreme values of surface variables (Fita et al. 2010) and was run through the WRF4G execution workflow (FernándezQuiruelas et al. 2010). Two different configurations were used in the simulations (labeled as WRF-A and WRF-B in Table 1). They only differ in the Planetary Boundary Layer (PBL) scheme. WRF-A uses a local scheme, whereas WRF-B uses a non-local scheme. MM5-UM is the climate version of the fifthgeneration Pennsylvania State University-NCAR mesoscale model (Dudhia 1993, Grell et al. 1994, Gómez-Navarro et al. 2010). The physical configuration (Table 1) has been chosen in order to minimise the computational cost, since none of the tested configurations provides the best performance for all kinds of synoptic events and regions of the IP (Fernández et al. 2007). REMO is a hydrostatic, 3-dimensional regional climate atmospheric model, developed at the Max-Planck-Institute for Meteorology in Hamburg. It is based on the Europa Model, a former numerical weather prediction model of the German Weather Service and it is described in Jacob (2001) and Jacob et al. (2001). REMO uses the physical package of the global circulation model ECHAM4 (Roeckner et al. 1996). All models are configured with a relaxation boundary of 8 to 10 grid points.

Table 1. Physics parameterizations used by the models in the simulations analyzed in the study. PBL: planetary boundary layer, LSM: Land Surface Model, CAM: Community Atmosphere Model

\begin{tabular}{|c|c|c|c|c|c|}
\hline Model & Microphysics & Cumulus & Radiation & PBL & Land surface \\
\hline PROMES & $\begin{array}{l}\text { Includes ice } \\
\text { processes (Hong } \\
\text { et al. 2004) }\end{array}$ & Kain \& Fritsch (1993) & $\begin{array}{l}\text { ECMWF (2004) with fractional } \\
\text { cloud cover (Chaboureau \& } \\
\text { Bechtold 2002, 2005) }\end{array}$ & $\begin{array}{l}\text { Cuxart et al. } \\
(2000)\end{array}$ & $\begin{array}{l}\text { ORCHIDEE LSM } \\
\text { (Krinner et al. 2005) }\end{array}$ \\
\hline WRF-A & $\begin{array}{l}\text { Single-moment 5- } \\
\text { class microphysics } \\
\text { (Hong \& Lim } \\
2006 \text { ) }\end{array}$ & $\begin{array}{l}\text { Grell \& Devenyi } \\
(2002)\end{array}$ & CAM 3.0 (Collins et al. 2006) & $\begin{array}{l}\text { Local Mellor- } \\
\text { Yamada-Janjic } \\
\text { (Janjić 1990, 1994) }\end{array}$ & $\begin{array}{l}\text { NOAH LSM } \\
\text { (Chen \& Dudhia } \\
\text { 2001a,b) }\end{array}$ \\
\hline WRF-B & $\begin{array}{l}\text { Single-moment 5- } \\
\text { class microphysics } \\
\text { (Hong \& Lim } \\
\text { 2006) }\end{array}$ & $\begin{array}{l}\text { Grell \& Devenyi } \\
(2002)\end{array}$ & CAM 3.0 (Collins et al. 2006) & $\begin{array}{l}\text { Non-local Yonsei } \\
\text { University (Hong } \\
\text { et al. 2006) }\end{array}$ & $\begin{array}{l}\text { NOAH LSM } \\
\text { (Chen \& Dudhia } \\
\text { 2001a,b) }\end{array}$ \\
\hline MM5 & $\begin{array}{l}\text { Simple ice } \\
\text { (Dudhia 1989) }\end{array}$ & Grell (1993) & $\begin{array}{l}\text { Rapid radiative transfer model } \\
\text { (RRTM) (Mlawer et al. 1997) }\end{array}$ & $\begin{array}{l}\text { Medium-range } \\
\text { forecast (MRF) } \\
\text { (Hong \& Pan 1996) }\end{array}$ & $\begin{array}{l}\text { NOAH LSM } \\
\text { (Chen \& Dudhia } \\
\text { 2001a,b) }\end{array}$ \\
\hline REMO & $\begin{array}{l}\text { Stratiform clouds } \\
\text { (Sundqvist 1978), } \\
\text { (Roeckner et al. } \\
\text { 1996) }\end{array}$ & $\begin{array}{l}\text { Mass flux convection } \\
\text { scheme after Tiedtke } \\
\text { (1989) with modifica- } \\
\text { tions after Nordeng } \\
(1994)\end{array}$ & $\begin{array}{l}\text { Morcrette et al. (1986) with } \\
\text { modifications after Giorgetta \& } \\
\text { Wild (1996) }\end{array}$ & $\begin{array}{l}\text { Higher-order } \\
\text { closure scheme } \\
\text { (Brinkop \& } \\
\text { Roeckner 1995) }\end{array}$ & $\begin{array}{l}\text { Types of vegetation } \\
\text { (FAO). Bucket } \\
\text { scheme for hydro- } \\
\text { logy. Five layers for } \\
\text { thermal processes }\end{array}$ \\
\hline
\end{tabular}




\subsection{Simulation set up}

The RCM simulations cover part of Europe, with a domain centered on the IP (Fig. 1 showing the land mask and orography for each model) and $25 \times 25 \mathrm{~km}$ of horizontal resolution in Lambert Conformal projection (PROMES, both versions of WRF and MM5) or in a rotated latitude-longitude coordinate system (REMO). The topography has been interpolated from GTOPO30 data (Verdin \& Greenlee 1996). The horizontal coordinates are arranged in Arakawa-B (MM5) or Arakawa-C (PROMES, REMO and both versions of WRF) grids. PROMES model used 37 sigma levels in the vertical, WRF 33, MM5 30 and REMO 31 levels (up to $10 \mathrm{hPa}$ for all models). The simulations cover the period from 1990 to 2007, with 1 yr of spin-up.

The ERA Interim reanalysis derived from the latest version of the operational ECMWF system has several differences to ERA-40 (Uppala et al. 2005), such as improvements in model physics, new humidity analysis, variational bias correction of satellite radiance data, among others (Dee \& Uppala 2009). In this study all models used boundary conditions from ERA-Interim with a spatial resolution of $0.7^{\circ} \times 0.7^{\circ}$, updated every $6 \mathrm{~h}$.

\subsection{Spain02 observation database}

The Spain02 precipitation and temperature database is a daily gridded dataset developed by Herrera et al. (2012) using surface station data from a set of

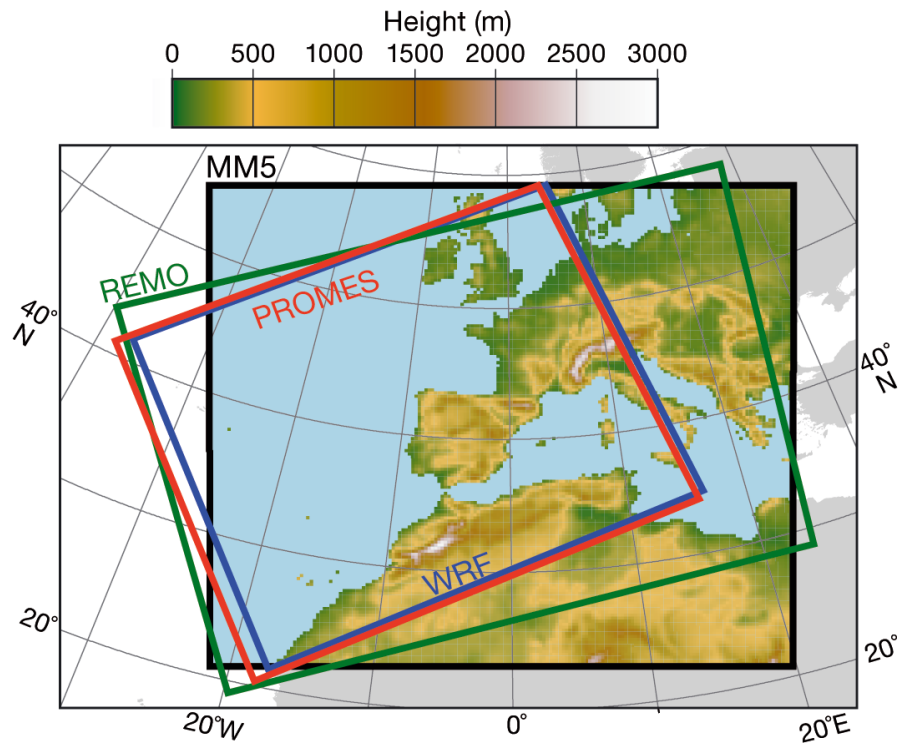

Fig. 1. Simulation domain of the 5 models used in the study: MM5, PROMES, REMO, WRF-A and -B
2756 quality-controlled stations over PS and the BA. There are currently insufficient surface observations to include the Canary Islands in the database. Here we present the most important features of this observational data. This data set spans from 1950 to 2008, with daily frequency and $0.2^{\circ} \times 0.2^{\circ}$ resolution. The fields were interpolated in a 2 -step process. First, the monthly means were interpolated using thin-plate splines. Second, daily departures from the monthly means were interpolated using a kriging methodology. In the case of precipitation, occurrence and amounts are interpolated through indicator and ordinary kriging, respectively. The interpolation procedure for precipitation is similar to that of the E-OBS European database (Haylock et al. 2008), except for the absence of the elevation-dependent splines applied to E-OBS database, which was not used in Spain02 (the topography is well represented by the large amount of stations).

For temperature, the Spain02 database applied a more stringent filter to the station data in order to provide a product better suited for trend analyses. Unlike the precipitation product, where the maximum number of available stations at a given day were used, the temperature data set was built from a reduced set of stations with the longest records. In particular, only those stations with a record longer than $40 \mathrm{yr}$ and $<1 \%$ of missing data were included in the interpolation. This led to a set of 186 stations. These stations were gridded using the same methodology as E-OBS (including the use of elevation as covariable, given the smaller amount of stations). The differences to E-OBS are the better quality and larger amount of stations. The large number of stations used in this product compared with E-OBS database, provides a better representation of the precipitation (Herrera et al. 2012) and temperature variability over Spain. Details of the interpolation procedure can be found in Herrera (2011) and Herrera et al. (2012).

\subsection{Statistical analysis}

The analyzed variables present a high spatial variability in a relatively small area, especially precipitation (Herrera et al. 2010). In the study of the climate features of a given region, information provided by the frequency distribution is complementary to simpler statistical analyses from which an integrated representation of climatic conditions over a region is provided (Giorgi et al. 2004a,b, Christensen \& Christensen 2007, Déqué et al. 2007, Jacob et al. 2007). 
Additionally, the use of subregions provides more useful results for some impact studies. Thus, our precipitation analysis was performed using the upper tail of the precipitation distribution for the subregions, and by examining the values of some standard extreme climate indices.

The probability density function (PDF) for precipitation was approximated by a histogram of the relative frequencies of daily precipitation amounts (days with precipitation $\geq 1 \mathrm{~mm}$ ) binned into $1 \mathrm{~mm} \mathrm{~d}^{-1}$ bins. A clearer visualization of the highest precipitation values is provided using a logarithmic scale. The PDFs are normalized by dividing by the total amount of precipitation data (1 value per day and grid point) in order to take into account the different size of the subregions. Comparison of the simulated results with observed values was performed using the PDFs calculated directly at the original grids for each subregion. Due to the similar resolution of both sources $\left(0.2^{\circ} \times 0.2^{\circ}\right.$ for Spain02 and $25 \times 25 \mathrm{~km}$ for RCMs $)$, the differences in subregion limits and extension are rather small among the different grids. This avoids the smoothing of extreme values which may arise from regridding.

In order to take into account the different precipitation regimes, the PDFs and the related analyses were carried out for different subregions obtained by grouping the 11 basins described in Herrera et al. (2010) according to the similarity of their annual cycles. In Fig. 2 these subregions are shown for the Spain02 grid; for the RCMs, equivalent subregions in the original grid of each model have been used. The 6 subregions are North (NO), Center-South (CE-SU), Levant (LE), Ebro (EB), Cataluña (CA) and the BA.

For the purpose of quantifying the overlap of the upper tail of the precipitation PDF between every RCM and Spain02, we applied a skill score (Perkins et al. 2007), previously used by Boberg et al. (2009), Boberg et al. (2010) and Kjellström et al. (2010). We introduced a small variation in Perkins' score, computing only the upper tail of the PDF, defined as the truncated PDF obtained using events larger than the 95th percentile of the observed precipitation. This metric has been calculated on all grid points and results are given as spatial averages for each subregion. It takes values between 0 to 1 , where 1 indicates maximum overlap.

Extreme temperatures are represented selecting different percentiles of daily maximum and minimum temperature depending on the season: the 10th percentile in winter (December to February) and the 90th percentile in summer (June to August). Moreover, in order to analyse extreme events in a comple-

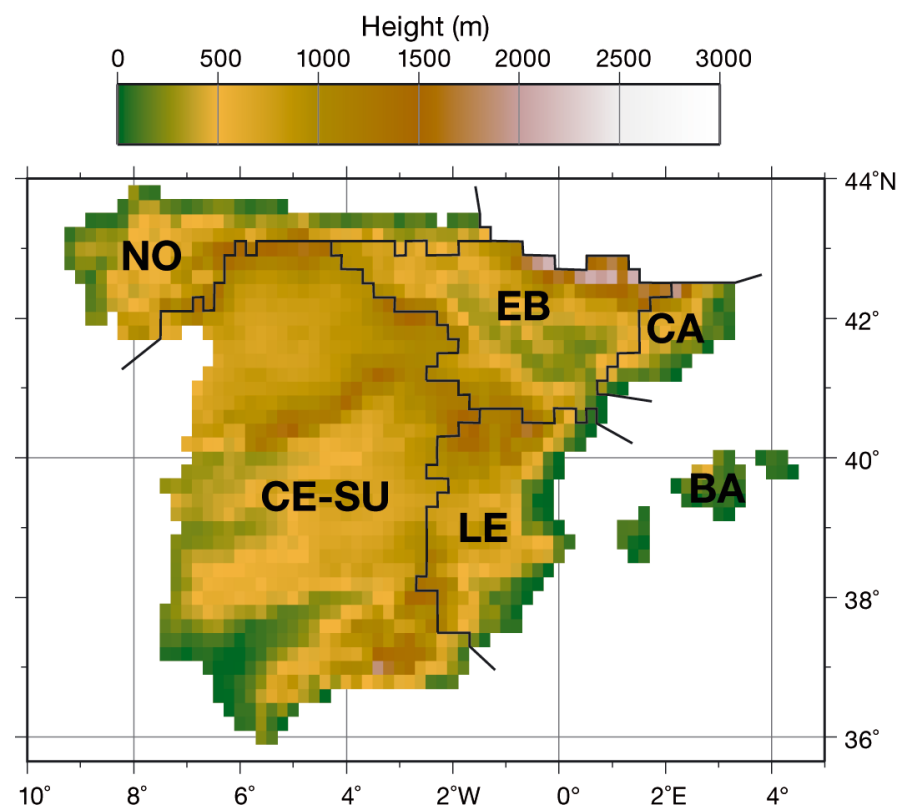

Fig. 2. Spain02 database orography and subregions: North (NO; 178 grid points), Center-South (CE-SU; 756), Levant (LE; 183), Ebro $(E B ; 234)$, Cataluña $(C A ; 57)$ and Balearic Islands $\left(\mathrm{BA}_{i} 37\right)$

mentary way, we used several indices (Klein Tank et al. 2009) applied over the IP by authors like de la Cruz Gallego et al. (2004), Sánchez et al. (2004), Gallego et al. (2005) and Herrera et al. (2010), among others. The selected indices are indicated in Table 2.

For precipitation, we selected medium-high intensity indices representing droughts or high intensity precipitation episodes. As frequency indices, we took the consecutive dry days $(<1 \mathrm{~mm})$ index (CDD) and the very heavy precipitation $(>20 \mathrm{~mm}$ ) days index (R20mm). As intensity index, we chose the fraction of precipitation due to events above the 95th percentile (R95PTOT). We calculated some other indices, but their spatial distribution was similar to the indices shown. All indices (see Table 2) are presented as yearly averages except R95PTOT.

For temperature, we used the yearly number of heat waves (HWn), the yearly maximum heat wave duration (HWd) and a set of temperature indices. A heat wave is defined as an event with maximum temperatures $>35^{\circ} \mathrm{C}$ during at least 5 consecutive days. This threshold has been calculated by averaging over the whole domain the 95th percentile of Spain02 climatology (1961 to 1990). These indices are more sensitive to model biases, since they are defined by absolute values rather than relative ones. The complementary temperature indices include the tropical nights index (TR) (number of days with minimum temperature $>20^{\circ} \mathrm{C}$ ) and the combined tropical 
Table 2. Precipitation and temperature extreme indices. Tx (Tn): maximum (minimum) temperature

\begin{tabular}{|c|c|c|}
\hline Index & Description & Units \\
\hline \multicolumn{3}{|c|}{ Precipitation } \\
\hline $\mathrm{CDD}$ & Consecutive dry days index (yearly mean) & $\mathrm{d} \mathrm{yr}^{-1}$ \\
\hline R20MM & Very heavy precipitation days index (yearly mean) & $\mathrm{d} \mathrm{yr}^{-1}$ \\
\hline R95PTOT & Precipitation fraction due to 95 percentile & $\%$ \\
\hline \multicolumn{3}{|c|}{ Temperature } \\
\hline HWd & Maximum heat wave duration per year (yearly mean) & $\mathrm{d} \mathrm{yr}^{-1}$ \\
\hline HWn & Heat wave number index (yearly mean) & heat waves $\mathrm{yr}^{-1}$ \\
\hline TR & Tropical nights index $\left(\operatorname{Tn}>20^{\circ} \mathrm{C}\right)$ & $\mathrm{d} \mathrm{yr}^{-1}$ \\
\hline $\mathrm{CHT}$ & Combined $\mathrm{HW}$ and $\mathrm{TR}\left(\mathrm{Tn}>20^{\circ} \mathrm{C}\right.$ and $\left.\mathrm{Tx}>35^{\circ} \mathrm{C}\right)$ & $\mathrm{d} \mathrm{yr}^{-1}$ \\
\hline
\end{tabular}

nights and summer days index (CHT, number of days with minimum temperature $>20^{\circ} \mathrm{C}$ and maximum temperature $>35^{\circ} \mathrm{C}$; Fischer \& Schär 2010).

The spatial representation of extreme indices is analysed with the Pearson correlation for the whole PS and BA. Regarding ensemble values, the ensemble mean of the models indices was calculated for each statistical index. In contrast, the PDF ensemble was created using all daily precipitation data from all the models without averaging.

\section{RESULTS}

\subsection{Precipitation}

\subsubsection{PDF tail analyses}

Fig. 3 shows the simulated precipitation PDF for the different RCMs, the multi-model ensemble and the observed Spain02 data for the 6 subregions. The large spatial variability of precipitation over the IP is clearly seen from the observed precipitation PDFs. Differences are relatively high: CE-SU subregion shows comparatively low frequency of the most extreme values (>100 $\mathrm{mm} \mathrm{d}^{-1}$ ), whereas LE, CA and BA show a relatively high frequency of such values. This reflects the division between Atlantic and Mediterranean precipitation regimes.

The spread of the simulated PDFs is highly dependent on the considered subregion. The lowest spread of the simulations is seen in the NO subregion. At the same time, differences between simulated and observed values are the lowest there, basically due to the small temporal variability in the area. Atlantic frontal systems are very frequent here. The precipitation associated with these systems is in general well represented by RCMs (Herrera et al. 2010). By contrast, Mediterranean subregions have a marked seasonal precipitation regime with high spatio-temporal variability. Extreme precipitation is quite often related to severe convective events which are more difficult to simulate by RCMs (e.g. Herrera et al. 2010). This result in a high spread of simulated precipitation for the CE-SU subregion. This area includes Atlantic basins, where precipitation is typically linked to Atlantic depressions; however, the seasonality of precipitation is much higher than for the NO subregion. Most models tend to underestimate precipitation for the CE-SU subregion, as found in previous studies (e.g. Herrera et al. 2010).

Fig. 3 also shows the 95th percentile of Spain02 data, used as the threshold for the modified Perkins score. Subregions like BA or CA have the highest 95th percentile values $\left(\sim 30 \mathrm{~mm} \mathrm{~d}^{-1}\right)$, while for the rest of the domain it most often does not exceed $25 \mathrm{~mm} \mathrm{~d}^{-1}$. Table 3 shows the calculated skill scores values. The values at the NO and CE-SU subregions are rather high $(\geq 0.90)$. The spread is smaller there than for the eastern part of PS. Maximum differences of about $25 \%$ are found at the BA. Subregions with higher spreads have lower scores. The RCMs present in general a good agreement with the observed PDF, with score values between 0.75 and 0.95 , except for the BA that have the lowest score $(<0.74$ for all models). These lower values could be related to the small number of grid points representing the islands, and the consequent worse representation of orography in this subregion. The ensemble scores are consistently higher than the scores obtained for the individual models.

\subsubsection{Extreme precipitation indices}

Regarding dry spells, the CDD index (Fig. 4, left column) has a spatial distribution with a strong north-south gradient. Center and South PS show the 


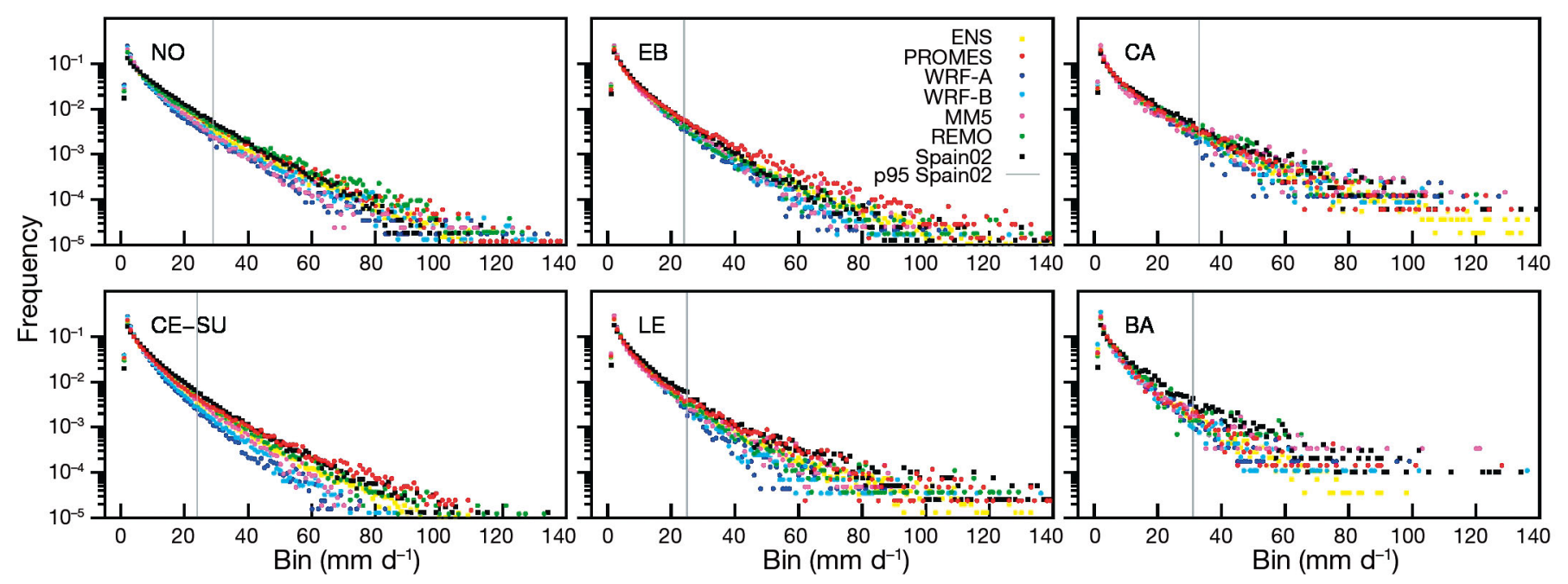

Fig. 3. Precipitation PDF of Spain02 data (black dots) and the 5 RCMs: PROMES (red), WRF-A (dark blue), WRF-B (light blue), MM5 (pink) and REMO (green), and the ensemble mean (ENS; yellow) over 6 Spanish subregions (North: NO, Center-South: CE-SU, Ebro: EB, Levant: LE, Cataluña: CA, Balearic Islands: BA) from January 1990 to December 2007. Gray lines: 95th percentile (p95) for each region

Table 3. Results for the modified Perkins' skill score (see Section 2.4) of extreme precipitation (higher than p95 of Spain02) for the 6 Spanish subregions (North: NO, CenterSouth: CE-SU, Levant: LE, Ebro: EB, Cataluña: CA, Balearic Islands: BA), the 5 RCMs (PROMES, WRF-A, WRF-B, MM5 and REMO) and the ensemble (ENS) mean

\begin{tabular}{|lcccccc|}
\hline & NO & CE-SU & LE & EB & CA & BA \\
\hline PROMES & 0.93 & 0.93 & 0.88 & 0.88 & 0.83 & 0.73 \\
WRF-A & 0.93 & 0.90 & 0.82 & 0.92 & 0.75 & 0.67 \\
WRF-B & 0.93 & 0.93 & 0.84 & 0.93 & 0.83 & 0.74 \\
MM5 & 0.92 & 0.92 & 0.87 & 0.94 & 0.80 & 0.61 \\
REMO & 0.90 & 0.96 & 0.89 & 0.91 & 0.82 & 0.55 \\
ENS & 0.94 & 0.97 & 0.91 & 0.94 & 0.86 & 0.79 \\
\hline
\end{tabular}

highest observed values, with maximum values $>100 \mathrm{~d} \mathrm{yr}^{-1}$. This reflects the summer dry period. Differences among RCMs are not high. Results show generally an underestimation of observed values over most of the domain, except some models (WRFA, WRF-B and REMO) in parts of the Mediterranean subregions (LE, CA and BA). RCMs and observations differ considerably in some areas, particularly near the Mediterranean southern coast, where for example PROMES or MM5 simulate values of $\sim 40 \%$ of the observed CDD. However, spatial correlations of $\sim 0.90$ for all models indicate a good concordance between observed and simulated spatial distributions of this index (see Fig. 7). The ensemble mean only gives a better value of the index in comparison with some models in certain subregions.
The observed spatial distribution for R20MM index and the corresponding model biases are shown in the middle column of Fig. 4. The highest values are found in the northern part of PS, in coherence with its precipitation regime. The next highest values are observed in mountainous areas of the CE-SU subregion, followed by CA subregion. The spatial distribution of this index shows no clear relationship to the distribution of CDD index, as high numbers of days $>20 \mathrm{~mm}$ occur both for low and high CDD areas. This illustrates well the large differences of rain regimes in this small domain. The smallest differences with respect to observations are obtained by PROMES, whereas the other RCMs underestimate this index, especially both versions of WRF model (spatial correlation values vary from 0.72 [WRF-A] to 0.79 [WRF-B]).

The R95PTOT index (Fig. 4, right column) is related to the heaviest precipitation events. Observed values obtained from Spain02 data show a clear maximum for the Mediterranean coastal areas. The RCMs are able to reproduce the observed climatic contrast between areas with high and low values of the heaviest rain events. However, they slightly overestimate this index over most of the domain. PROMES and MM5 show the largest positive bias extending over the widest areas. WRF-A values are the closest of all models to the observed data over most of the domain. The R95PTOT spatial correlations (see Fig. 7) are the lowest among all precipitation indices. These low R95PTOT correlation values could indicate the difficulty of simulating the precise spatial location of heavy convective events using RCMs. 

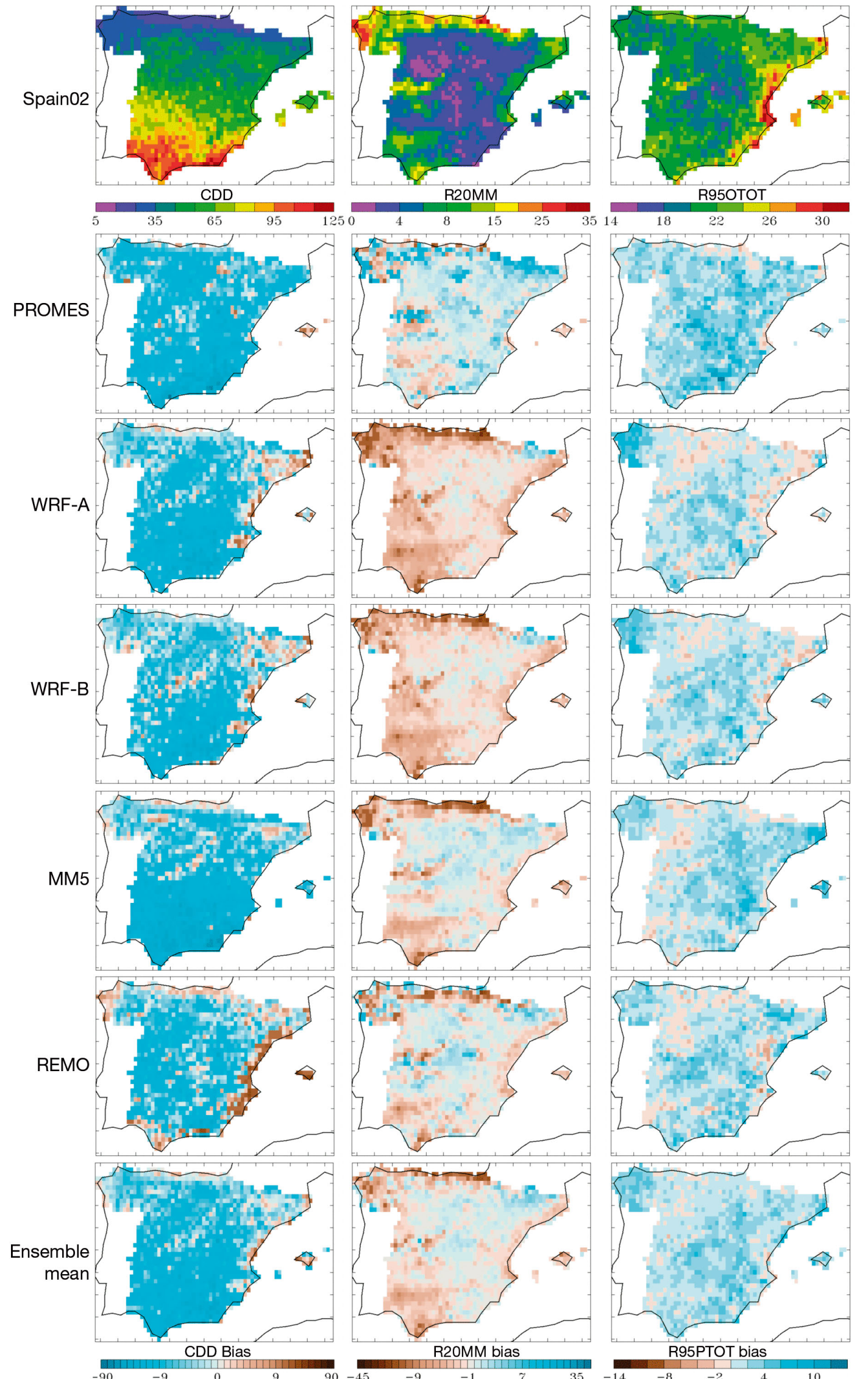

Fig. 4. Spatial distribution of precipitation extreme indices (CDD: consecutive dry days index, R20MM: very heavy precipitation days index, and R95PTOT: precipitation fraction due to 95th percentile) of Spain02 data (1st row) and the RCM biases for PROMES, WRF-A, WRF-B, MM5, REMO and the ensemble mean (rows 2-7, respectively) from January 1990 to December 2007 


\subsection{Maximum and minimum temperature}

\subsubsection{Seasonal percentiles}

Fig. 5 presents the seasonal percentiles for maximum (Tx) and minimum (Tn) temperature. The first and second columns show the 10th percentile respectively of maximum (Tx10) and minimum (Tn10) temperatures in winter. Spain02 shows the lowest values of Tx10 in the northern part of PS (reaching $-3^{\circ} \mathrm{C}$ in the Pyrenees) while the lowest values (down to $-10^{\circ} \mathrm{C}$ ) for $\operatorname{Tn} 10$ are found in the central-eastern highlands around the Iberian Mountain Range. This reflects the continental characteristics of the interior climate (Castro et al. 2007). The 90th percentile for maximum (Tx90) and minimum (Tn90) temperatures in summer are represented in the third and fourth columns of Fig. 5. The highest values of $\operatorname{Tx} 90\left(\sim 40^{\circ} \mathrm{C}\right)$ appear in the CE-SU subregion of the IP, related to the typical summer thermal lows over this area (Hoinka \& de Castro 2003). The thermal inertia of the oceans leads to smaller differences between Tx90 and Tn90 in coastal areas (with values between 4 and $14^{\circ} \mathrm{C}$ in NO, LE and CA subregions, not shown) and to higher differences in continental areas (with values between 14 and $24^{\circ} \mathrm{C}$ in CE-SU and EB subregions).

In general, a similar spatial distribution was obtained for all models, with a low spread among them, except for REMO Tn percentiles. The spatial distribution of the Spain02 percentiles was generally well reproduced by the models. The highest correlation was found for Tx (see Fig. 7). Correlation values obtained for percentiles of Tx are 0.83 to 0.95 , and 0.79 to 0.86 for Tn percentiles. REMO has the lowest values for cold nights (0.79).

Most of the RCMs underestimate the Tx10 values, with moderate differences in some areas. REMO is the model with values closer to Spain02. Both versions of WRF and MM5 also underestimate the Tx90, while PROMES matches Spain02 percentiles in the western part of PS and overestimates them, particularly on the Mediterranean coast and the BA. Regarding minimum temperature percentiles, the values obtained by REMO are higher than the simulated by the rest of models, and also higher than the observations in most of the domain, as discussed below. These biases of REMO reach up to $10^{\circ} \mathrm{C}$ in areas where these percentiles reach their minimum values.

\subsubsection{Extreme temperature indices}

Fig. 6 presents the indices that have been used to describe temperature extreme events like heat waves (defined in Table 2). Spain02 shows that the highest heat wave frequency ( $\mathrm{HWn}$; first column) is located in the CE-SU subregion (up to 5 heat waves $\mathrm{yr}^{-1}$ ), with a maximum duration ( $\mathrm{HWd}_{\text {; }}$ second column) that varies between 6 and $16 \mathrm{~d}$ in PS. It should be noted that these indices are sensitive to model biases as they are related to a fixed observational threshold.

The spread of HWn values is large among the RCMs. There is some tendency of the models to underestimate this index compared with observations, with the exception of PROMES and REMO, which overestimate the number of heat waves particularly in southern and eastern coastal areas. The models which underestimate the number of heat waves also tend to underestimate their duration. In contrast, PROMES and REMO simulate longer than observed heat waves, especially over the southwestern part of PS. The spatial distribution of these indices presents correlation values between 0.43 ( $\mathrm{HWd}$ for WRF-A) and 0.88 (HWn for MM5) (Fig. 7); HWd is the index with the lowest spatial correlation values for all models.

Fig. 6 also shows other indices related to factors that have a social and economical impact on the studied area (AEMET 2007, Fischer \& Schär 2010): TR (third column) and CHT (last column), defined in Table 2 .

Spain02 present the highest TR value in the eastern coasts and the $\mathrm{BA}$, with $>100 \mathrm{~d} \mathrm{yr}^{-1}$. Values around 20 or $30 \mathrm{~d} \mathrm{yr}^{-1}$ are observed in most of the southern half of PS and the Ebro valley, while in the remaining areas TR has a value of $<2 \mathrm{~d} \mathrm{yr}^{-1}$. The thresholds used to compute CHT are the same as those used for TR and HW, but the spatial distribution of the CHT index is more similar to HWn than to the TR index, with highest values in CE-SU subregion (up to $40 \mathrm{~d} \mathrm{yr}^{-1}$ ). This fact highlights the need for studying the TR index separately in extreme temperature analysis. For instance, in the case of the BA, the value of TR is $>100 \mathrm{~d} \mathrm{yr}^{-1}$, while CHT is $<15 \mathrm{~d} \mathrm{yr}^{-1}$.

Differences of TR values among RCMs are related to the differences obtained for Tn90 index (see last column in Fig. 5), with higher values for the BA and the southern part of PS. In general, all the models underestimate TR in the central area of PS except REMO, which overestimates this index in most of the domain. CHT is also clearly overestimated by REMO in many parts of PS, reaching values up to 3 times higher than the observed ones. If we consider the biases of maximum and minimum temperature percentiles (Fig. 5), this latter bias is probably more related to the minimum temperature biases. Higher 

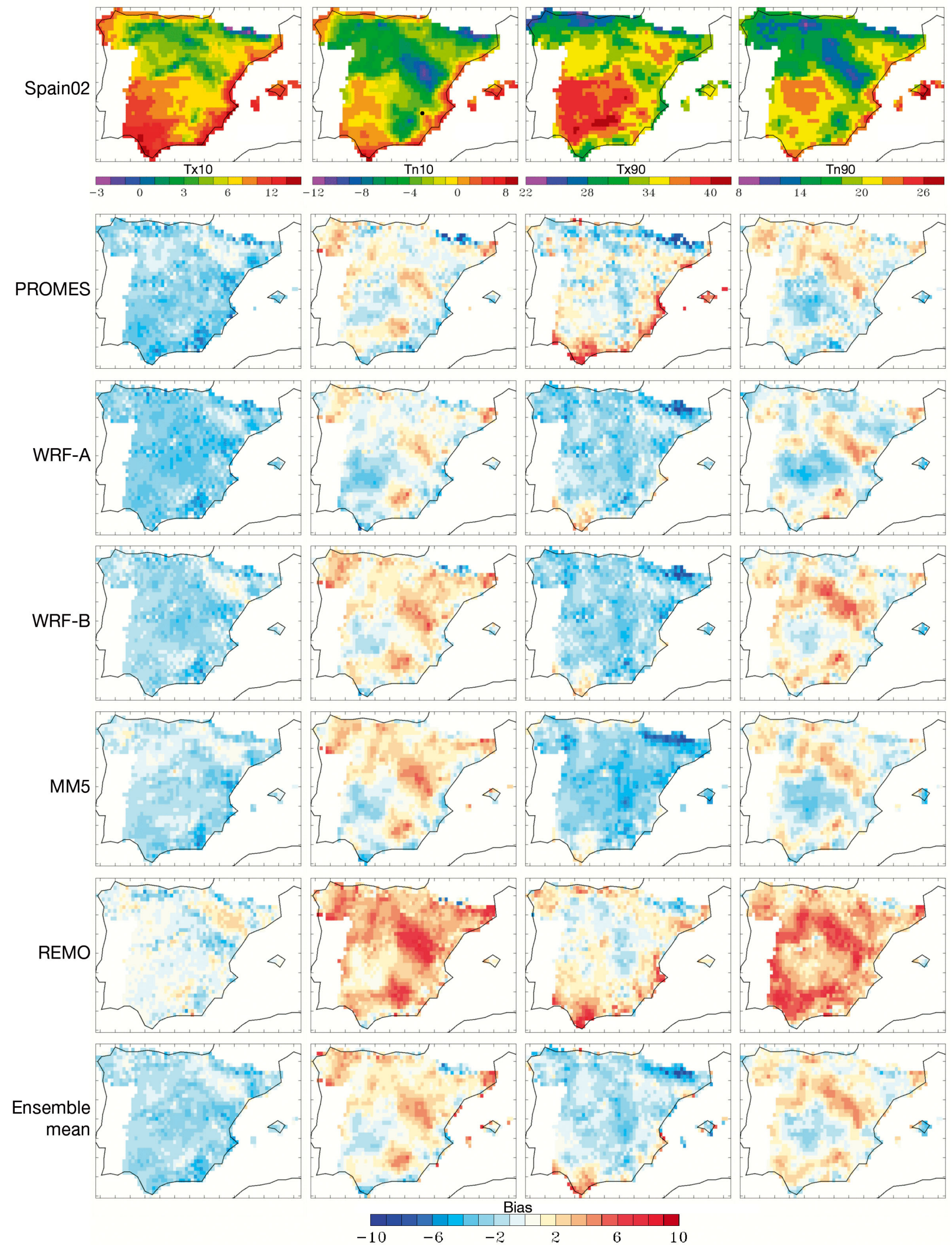

2

$6 \quad 10$

Fig. 5. Spatial distribution for temperature seasonal percentiles: Tx10 (Tn10) $=10$ th percentile for maximum (minimum) temperatures for winter; Tx90 $($ Tn90 $)=90$ th percentile for maximum (minimum) temperature for summer. Top row: Spain02 data. Rows 2-7: RCM biases for PROMES, WRF-A, WRF-B, MM5, REMO and the ensemble mean 

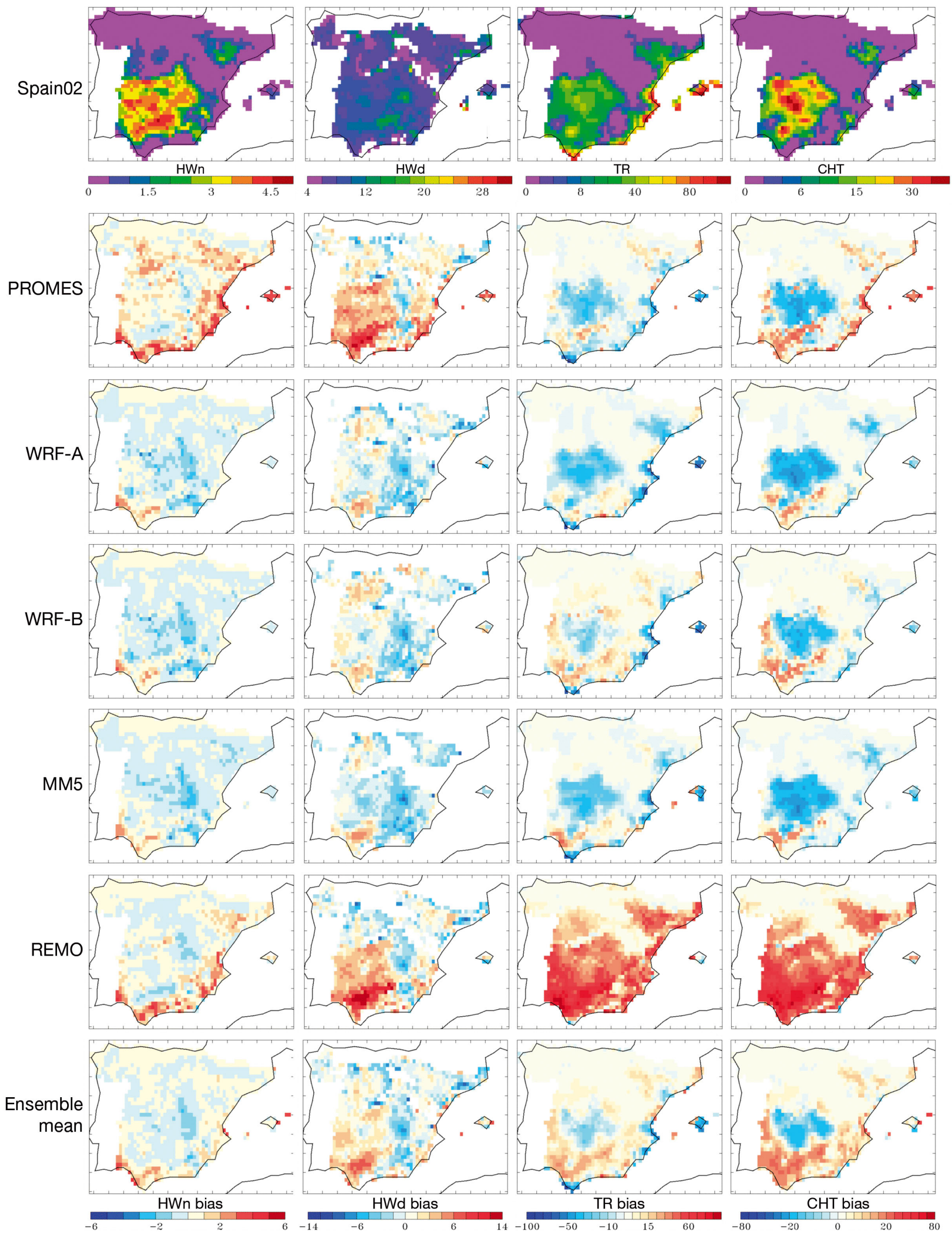

Fig. 6. Spatial distribution for yearly heat wave indices: HWn (heat wave frequency), HWd (heat wave duration), tropical nights (TR), combined tropical, and summer days (CHT). Top row: Spain02, Rows 2-7: RCM biases for PROMES, WRF-A, WRF-B, MM5, REMO and the ensemble mean 


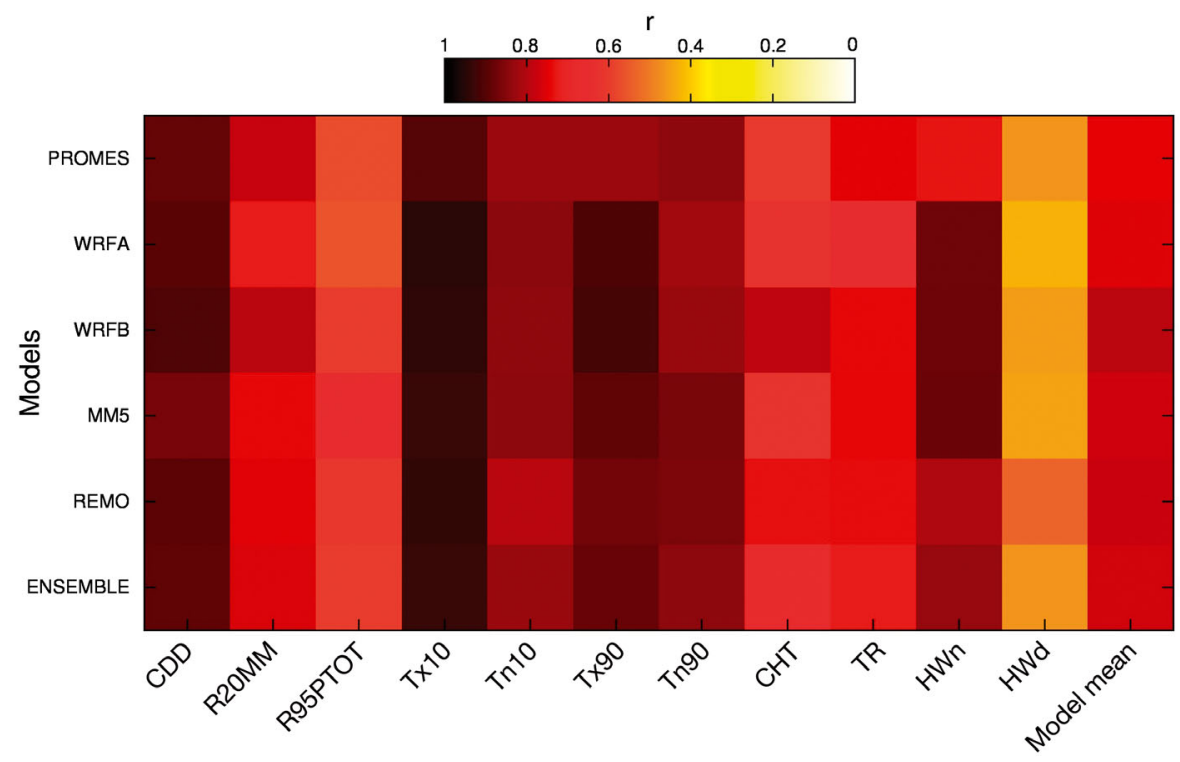

Fig. 7. Spatial correlations between simulated and observed precipitation and temperature indices of the 5 RCMs (PROMES, WRF-A, WRF-B, MM5 and REMO) and the ensemble mean, and the mean correlation of all indices for each model (last column). Index definitions in Table 2 and Fig. 5

than observed values are also simulated by PROMES in the southern and eastern coasts. This positive bias for PROMES is also noticeable in the BA, which is in agreement with Tx90 percentile (Fig. 5) and HWn and HWd indices (Fig. 6). All models except REMO underestimate $\mathrm{CHT}$ for the area with the highest observed values of this index. Spatial correlations for both indices vary between 0.60 and 0.79 . The ensemble mean of the CHT index does not present an important improvement compared to the results of the individual models.

\section{DISCUSSION AND CONCLUSIONS}

We have analyzed the ability of 4 RCMs (WRF, MM5, PROMES and REMO) to reproduce climate extremes in an evaluation simulation over PS and the BA, for the period 1990-2007. This work is part of a Spanish project (ESCENA) for generating a set of regional climate change scenarios over this region. In comparison to previous climate validation studies over this domain, there are important differences: the domain is centered over the IP, unlike the domain used in ENSEMBLES project in which the lateral boundaries were very near to this region, and the models are nested in the ERA-Interim reanalysis. The multi-model ensemble also includes WRF (WRF-A and $-\mathrm{B}$, with different PBL schemes) and MM5, which were not included in ENSEMBLES.
There is a very large range of precipitation regimes in this small analyzed region. Three areas stand out for at least one of the extreme indices: the northern coast, the southwestern area and the Mediterranean coast. The northern coast is an area with low CDD and high R20MM values. Precipitation occurs throughout the year, and the interannual variability (shown in the companion paper, JiménezGuerrero et al. 2013) is rather low. For this regime, the spread of the model results is the lowest, as indicated by the Perkins skill score (Table 3). CDD and R95PTOT are rather well reproduced by all models, but they clearly differ in the R20MM index, for which several models show an important negative bias.

By contrast, the spread of the results for the southwestern area is higher, and there is a clear tendency of most models to underestimate precipitation. This occurs despite the fact that the PDF shows comparatively low frequency for very high precipitation values, and therefore model errors cannot be linked mainly to problems in simulating very heavy convective precipitation events. This is an area where model biases in a previous study with ENSEMBLES project results (Herrera et al. 2010) were also large. A possible reason for those biases in ENSEMBLES simulations could have been the proximity of lateral boundaries, or limitations of moisture values of ERA40 reanalysis. ERA-Interim, among other improvements, has introduced a new humidity analysis. But the present setup, with western lateral boundaries far away from this region and nesting in ERA-Interim, does not improve previous results. We can obtain more information about biases in this area from the companion paper (Jiménez-Guerrero et al. 2013). As shown there, the interannual variability is high and is not well captured by most models. But at the same time, results shown in this companion paper indicate that all models show high temporal correlations. This suggests that the timing of precipitation events is well captured (a result that could be linked to the fact that major precipitation events are frequently due to large scale Atlantic depressions), but the precipitation amounts are not. The fact that there is one model (PROMES) showing better results over this area indicates that the negative bias could be associated with some aspect of the model formulation. 
For the Mediterranean coast, the number of days with $>20 \mathrm{~mm}$ of precipitation is smaller than for the southwestern part, but R95PTOT is much larger, and the PDF tails show a large frequency of very high precipitation. A similar negative bias in R20MM can be seen for all models except PROMES, but R95PTOT is rather well captured by all models. In contrast to the southwestern area, the temporal correlation (Jiménez-Guerrero et al. 2013) is much lower for all the models here. This indicates that the errors for the Mediterranean coast are also linked to deficiencies in the simulation of the temporal distribution of precipitation. An interesting result, specific to the Mediterranean subregions, is that the ensemble mean is worse than the individual models in representing the frequency of very high precipitation events. The ensemble mean underestimates this frequency. A possible reason is that strong convective events are spatially localized, and the specific locations are simulated differently by the models. Thus, the average would tend to smooth out these very high precipitation amounts.

Modelled values of maximum temperature percentiles are generally lower than observed, with the exception of REMO. By contrast, this model shows a considerable overestimation of minimum temperature percentiles and of TR and CHT indices, indicating a problem with minimum temperatures. The REMO version used here already includes the improvements discussed in Kjellström et al. (2010) for winter minimum temperatures. The present biases in REMO results must have different causes, which are still unknown. The spatial distribution of temperature percentiles is particularly well simulated by all models, as illustrated by the high spatial correlation values.

ESCENA also explored a very limited part of the uncertainty accounted for by the physical parameterizations using the WRF model in 2 configurations. The differences between the local and non-local PBL closure schemes used are most noticeable in the minimum temperature indices, since the local closure configuration (WRF-A) shows a weaker low level mixing during nighttime (García-Díez et al. 2013), which leads to cooler minimum temperatures (and associated percentiles). WRF-B used a non-local closure scheme, very similar to that used by MM5, leading to very similar biases in the winter cold extremes (Fig. 5, Tn10).

The present multi-model ensemble can be compared to the one of ENSEMBLES project (Herrera et al. 2010). The spatial correlations of the precipitation indices of models involved in both projects (PROMES and REMO) are similar in both cases. In the case of ENSEMBLES models, for some indices there was a clear division between models with high and low correlation values. In particular, results for R20MM index can be compared directly. The comparison indicates that all models of the present ensemble are at a similar level to the best subgroup of ENSEMBLES models, and clearly above the worse models of that project. Therefore, the ESCENA simulations (covering more emissions scenarios and GCMs) can be considered a valuable complement to the ENSEMBLES results for impact studies over Spain.

Acknowledgements. The Spanish Ministerio de Medio Ambiente y Medio Rural y Marino funded this research through project ESCENA (Ref: 200800050084265). REMO results (from UAH) were obtained through the Spanish project CGL2008-05112-C02-02. Project CGL2010-18013, financed by the Spanish Ministerio de Economía y Competitividad, also contributed to this study.

\section{LITERATURE CITED}

AEMET (Agencia Estatal de Meteorología) (2007) Resumen de extremos climatológicos en España (2007). AEMET (in Spanish)

Alexander L, Zhang X, Peterson T, Caesar J and others (2006) Global observed changes in daily climate extremes of temperature and precipitation. J Geophys Res 111:D05109, doi:10.1029/2005JD0062 90

Barriopedro D, Fischer E, Luterbacher J, Trigo R, GarcíaHerrera R (2011) The hot summer of 2010: redrawing the temperature record map of Europe. Science 332:220-224

Beniston M (2006) August 2005 intense rainfall event in Switzerland: not necessarily an analog for strong convective events in a greenhouse climate. Geophys Res Lett 33:L05701, doi:10.1029/2005GL025573

> Beniston M, Stephenson DB (2004) Extreme climatic events and their evolution under changing climatic conditions. Global Planet Change 44:1-9

Beniston M, Stephenson DB, Christensen OB, Ferro CAT and others (2007) Future extreme events in European climate: an exploration of regional climate model projections. Clim Change 81:71-95

Boberg F, Berg P, Thejll P, Gutowski WJ, Christensen JH (2009) Improved confidence in climate change projections of precipitation evaluated using daily statistics from the PRUDENCE ensemble. Clim Dyn 32:1097-1106

Boberg F, Berg P, Thejll P, Gutowski WJ, Christensen JH (2010) Improved confidence in climate change projections of precipitation further evaluated using daily statistics from ENSEMBLES models. Clim Dyn 35:1509-1520

Brinkop S, Roeckner E (1995) Sensitivity of a general circulation model to parameterizations of cloud-turbulence interactions in the atmospheric boundary layer. Tellus A 47:197-220

Brunetti M, Colacino M, Maugeri M, Nanni T (2001) Trends in the daily intensity of precipitation in Italy from 1951 to 1996. Int J Climatol 21:299-316

Castro M, Fernández C, Gaertner MA (1993) Description of 
a mesoscale atmospheric numerical model. In: Diaz JI, Lions Jl (eds) Mathematics, climate and environment. Mason, Paris, p 230-253

> Castro M, Gallardo C, Jylhä K, Tuomenvirta H (2007) The use of a climate-type classification for assessing climate change effects in Europe from an ensemble of nine regional climate models. Clim Change 81(S1):329-341

> Chaboureau JP, Bechtold P (2002) A simple cloud parameterization derived from cloud resolving model data: diagnostic and prognostic applications. J Atmos Sci 59: 2362-2372

> Chaboureau JP, Bechtold P (2005) Statistical representation of clouds in a regional model and the impact on the diurnal cycle of convection during Tropical Convection, Cirrus and Nitrogen Oxides (TROCCINOX). J Geophys Res 110:D17103, doi:10.1029/2004JD005645

> Chen F, Dudhia J (2001a) Coupling an advanced land surface-hydrology model with the Penn State-NCAR MM5 modeling system. I. Model implementation and sensitivity. Mon Weather Rev 129:569-585

> Chen F, Dudhia J (2001b) Coupling an advanced land surface-hydrology model with the Penn State-NCAR MM5 modeling system. II. Preliminary model validation. Mon Weather Rev 129:587-604

Christensen JH, Christensen OB (2007) A summary of the PRUDENCE model projection of changes in European climate by the end of this century. Clim Change 81:1-30

> Collins WD, Rasch PJ, Boville BA, Hack JJ, McCaa JR, Williamson DL, Briegleb BP (2006) The formulation and atmospheric simulation of the Community Atmosphere Model version 3 (CAM3). J Clim 19:2144-2161

> Cuxart J, Bougeault P, Redelsperger JL (2000) A turbulence scheme allowing for mesoscale and large-eddy simulations. QJR Meteorol Soc 126:1-30

de la Cruz Gallego M, García JAG, Vaquero JM (2004) Distribución espacial de índices de frecuencia de precipitación diaria en la Peninsula Ibérica. Física de la Tierra 16: 161-174

> Dee DP, Uppala S (2009) Variational bias correction of satellite radiance data in the ERA-Interim reanalysis. QJR Meteorol Soc 135:1830-1841

> Della-Marta P, Haylock M, Luterbacher J, Wanner H (2007) Doubled length of western European summer heat waves since 1880. J Geophys Res 112:D15103, doi:10. 1029/2007JD008510

> Déqué M, Rowell DP, Lthi D, Giorgi F and others (2007) An intercomparison of regional climate simulations for Europe: assessing uncertainties in model projections. Clim Change 81(S1):53-70

> Domínguez M, Gaertner M, De Rosnay P, Losada T (2010) A regional climate model simulation over West Africa: parameterization tests and analysis of land-surface fields. Clim Dyn 35:249-265

> Dudhia J (1989) Numerical study of convection observed during the winter monsoon experiment using a mesoscale two-dimensional model. J Atmos Sci 46:3077-3107

Dudhia J (1993) A nonhydrostatic version of the Penn StateNCAR mesoscale model: validation tests and simulation of an Atlantic cyclone and cold front. Mon Weather Rev 121:1493-1513

ECMWF (European Centre for Medium-Range Weather Forecasts) (2004) IFS documentation CY28r1. ECMWF, Reading, p 7-32, www.ecmwf.int/research/ifsdocs/CY28r1/ pdf_files/Physics.pdf

Fernández J, Montávez JP, Sáenz J, González-Rouco JF,
Zorita E (2007) Sensitivity of the MM5 mesoscale model to physical parameterizations for regional climate studies: annual cycle. J Geophys Res 112(D4):D04101, doi: 10.1029/2005JD006649

Fernández-Quiruelas V, Fita L, Fernández J no AC (2010) WRF workflow on the Grid with WRF4G. Proc 11th WRF Users' Workshop, 21-25 June, Boulder, CO. www.meteo. unican.es/files/pdfs/WRFusers_wrf4g.pdf

Field C, Barros V, Stocker T, Qin D and others (eds) (2012) Managing the risks of extreme events and disasters to advance climate change adaptation. A Special Report of Working Groups I and II of the Intergovernmental Panel on Climate Change. Cambridge University Press, Cambridge

> Fischer EM, Schär C (2010) Consistent geographical patterns of changes in high-impact European heatwaves. Nat Geosci 3:398-403

> Fischer EM, Seneviratne SI, Lüthi D, Schär C (2007) Contribution of land-atmosphere coupling to European summer heat waves. Geophys Res Lett 34:L06707, doi:10. 1029/2006GL029068

Fita L, Fernández J, García-Díez M (2010) CLWRF: WRF modifications for regional climate simulation under future scenarios. Proc 11th WRF Users' Workshop, 21-25 June, Boulder, CO

Frei C, Schöll R, Fukutome S, Schmidli J, Vidale PL (2006) Future change of precipitation extremes in Europe: intercomparison of scenarios from regional climate models. J Geophys Res 111:D06105, doi:10.1029/2005JD005965

Frich P, Alexander LV, Della-Marta P, Gleason B, Haylock M, Klein Tank AM, Peterson T (2002) Observed coherent changes in climatic extremes during the second half of the twentieth century. Clim Res 19:193-212

Gallego MC, García JA, Vaquero JM (2005) The NAO signal in daily rainfall series over the Iberian Peninsula. Clim Res 29:103

> García-Díez M, Fernández J, Fita L, Yagüe C (2013) Seasonal dependence of WRF model biases and sensitivity to PBL schemes over Europe. QJR Meteorol Soc 139:501-514

García-Herrera R, Díaz J, Trigo R, Hernández E and others (2005) Extreme summer temperatures in Iberia: health impacts and associated synoptic conditions. Ann Geophys 23:239-251

Giorgetta M, Wild M (1996) The water vapour continuum and its representation in ECHAM4. MPI Rep 162

Giorgi F, Bi X, Pal JS (2004a) Mean, interannual variability and trends in a regional climate change experiment over Europe. I. Present-day climate (1960-1990). Clim Dyn 22:733-756

Giorgi F, Bi X, Pal JS (2004b) Mean, interannual variability and trends in a regional climate change experiment over Europe. II. Climate change scenario (2071-2100). Clim Dyn 23:839-858

Giorgi F, Jones C, Asrar G (2009) Addressing climate information needs at the regional level: the CORDEX framework. WMO Bulletin 58:3

Gómez-Navarro JJ, Montávez JP, Jiménez-Guerrero P, Jerez S, García-Valero JA, González-Rouco JF (2010) Warming patterns in a regional climate projections over the Iberian Peninsula. Met Zeit 19:275-285

González-Hidalgo JC, De Luis M, Raventós J, Sánchez JR (2003) Daily rainfall trend in the Valencia region of Spain. Theor Appl Climatol 75:117-130, www.ua.es/ personal/martin.deluis/Gonzalez-Hidalgo \%20et\%20al., $\% 202003 \% 20$ (TAC).PDF 
Grell GA (1993) Prognostic evaluation of assumptions used by cumulus parameterizations. Mon Weather Rev 121: 764-787

Grell GA, Devenyi D (2002) A generalized approach to parameterizing convection combining ensemble and data assimilation techniques. Geophys Res Lett 29:L1693, doi: 10.1029/2002GL015311

Grell GA, Dudhia J, Stauffer DR (1994) A description of the fifth-generation Penn State/NCAR mesoscale model (MM5). Tech Note TN-398+ IA. NCAR:1-125

Haylock MR, Hofstra N, Klein-Tank AMG, Klok EJ, Jones PD, New M (2008) A European daily high-resolution gridded data set of surface temperature and precipitation for 1950-2006. J Geophys Res 113:D20119, doi:10.1029/ 2008JD010201

Herrera S (2011) Desarrollo, validación y aplicaciones de Spain02: una rejilla de alta resolución de observaciones interpoladas para precipitación y temperatura en España. $\mathrm{PhD}$ thesis, Universidad de Cantabria, available at www. meteo.unican.es/tesis/herrera

Herrera S, Fita L, Fernández J, Gutiérrez JM (2010) Evaluation of the mean and extreme precipitation regimes from the ENSEMBLES regional climate multimodel simulations over Spain. J Geophys Res 115:D21117, doi:10. 1029/2010JD013936

> Herrera S, Gutiérrez JM, Ancell R, Pons MR, Frías MD, Fernández J (2012) Development and analysis of a 50-year high-resolution daily gridded precipitation dataset over Spain (Spain02). Int J Climatol 32:74-85

> Hirschi M, Seneviratne SI, Alexandrov V, Boberg F and others (2010) Observational evidence for soil-moisture impact on hot extremes in southeastern Europe. Nat Geosci 4:17-21

Hoinka KP, de Castro M (2003) The Iberian peninsula thermal low. QJR Meteorol Soc 129:1491-1511

Hong SY, Lim JOJ (2006) The WRF Single-Moment 6-Class Microphysics Scheme (WSM6). J Korean Meteorol Soc 42:129-151

Hong SY, Pan HL (1996) Nonlocal boundary layer vertical diffusion in a medium-range forecast model. Mon Weather Rev 124:2322-2339

Hong S, Dudhia J, Chen S (2004) A revised approach to ice microphysical processes for the bulk parameterization of cloud and precipitation. Mon Weather Rev 132:103-120

Hong SY, Noh Y, Dudhia J (2006) A new vertical diffusion package with an explicit treatment of entrainment processes. Mon Weather Rev 134:2318-2341

Huth R, Kyselý J, Pokorná L (2000) A GCM simulation of heat waves, dry spells, and their relationships to circulation. Clim Change 46:29-60

IPCC (2001) Climate Change 2001: the scientific basis. Contribution of Working Group I to the Third Assessment Report of the Intergovernmental Panel on Climate Change. Houghton JT, Ding Y, Griggs DJ, Noguer M and others (eds) Cambridge University Press, Cambridge

IPCC (2007) Climate Change 2007: the physical science basis. Contribution of Working Group I to the Fourth Assessment Report of the Intergovernmental Panel on Climate Change. Solomon S, Quin D, Manning M, Chen Z and others (eds) Cambridge University Press, Cambridge

$>$ Jacob D (2001) A note to the simulation of the annual and inter-annual variability of the water budget over the Baltic Sea drainage basin. Meteorol Atmos Phys 77:61-73

- Jacob D, Van den Hurk B, Andrae U, Elgered G and others (2001) A comprehensive model inter-comparison study investigating the water budget during the BALTEXPIDCAP period. Meteorol Atmos Phys 77:19-43

> Jacob D, Barring L, Christensen OB, Christensen JH and others (2007) An inter-comparison of regional climate models for Europe: model performance in present-day climate. Clim Change 81(S1):31-52

Janjić ZI (1990) The Step-Mountain Coordinate: physical package. Mon Weather Rev 118:1429-1443

Janjić ZI (1994) The Step-Mountain Eta coordinate model: further developments of the convection. Mon Weather Rev 122:927-945

Jiménez-Guerrero P, Montávez JP, Domínguez M, Romera R and others (2013) Mean fields and interannual variability in RCM simulations over Spain: ESCENA project. Clim Res 57:201-220

Kain JS, Fritsch JM (1993) Convective parameterization for mesoscale models: the Kain-Fritsch scheme. The representation of cumulus convection in numerical models. Am Meteorol Soc 46:165-170

> Kjellström E, Boberg F, Castro M, Christensen JH, Nikulin G, Sánchez E (2010) Daily and monthly temperature and precipitation statistics as performance indicators for regional climate models. Clim Res 44:135-150

Klein Tank AMG, Zwiers FW, Zhang X (2009) Guidelines on analysis of extremes in a changing climate in support of informed decisions for adaptation. Climate Data and Monitoring, WCDMP 72:WMO-TD No. 1500, WMO, Geneva, www.wmo.int/pages/prog/wcp/wcdmp/wcdmp _series/documents/WCDMP_72_TD_1500_en_1.pdf

Krinner G, Viovy N, de Noblet-Ducoudré N, Ogée J and others (2005) A dynamic global vegetation model for studies of the coupled atmosphere-biosphere system. Global Biogeochem Cycles 19:GB1015, doi:10.1029/2003GB002199

Kysely J, Plavcova E (2010) A critical remark on the applicability of E-OBS European gridded temperature dataset for validating control climate simulations. J Geophys Res 115:D23118, doi:10.1029/2010JD014123

> Lana X, Martínez MD, Burgueño A, Serra C, Martín-Vide J, Gómez L (2006) Distributions of long dry spells in the Iberian Peninsula, years 1951-1990. Int J Climatol 26: 1999-2021

> López-Moreno JI, Beniston M (2009) Daily precipitation intensity projected for the 21st century: seasonal changes over the Pyrenees. Theor Appl Climatol 95:375-384

> Martin-Vide J (2004) Spatial distribution of a daily precipitation concentration index in peninsular Spain. Int J Climatol 24:959-971

> Mlawer EJ, Taubman SJ, Brown PD, Iacono MJ, Clough SA (1997) Radiative transfer for inhomogeneous atmospheres: RRTM, a validated correlated-k model for the longwave. J Geophys Res 102(D14):16663-16682

Morcrette JJ, Smith L, Fourquart Y (1986) Pressure and temperature dependance of the absorption in longwave radiation parameterizations. Beitr Phys Atmos 59:455-469

Nordeng TE (1994) Extended versions of the convective parametrization scheme at ECMWF and their impact on the mean and transient activity of the model in the tropics. Tech Rep ECMWF, Tech Memo No. 206, Reading

Perkins SE, Pitman AJ, Holbrook NJ, McAneney J (2007) Evaluation of the AR4 climate models' simulated daily maximum temperature, minimum temperature, and precipitation over Australia using probability density functions. J Clim 20:4356-4376

Roeckner E, Arpe K, Bengtsson L, Christoph M and others (1996) The atmospheric general circulation model 
ECHAM-4: model description and simulation of presentday climate. MPI Meteorol Rep 218, Hamburg

Sánchez E, Gallardo C, Gaertner MÁ, Arribas A, de Castro $M$ (2004) Future climate extreme events in the Mediterranean simulated by a regional climate model: a first approach. Global Planet Change 44:163-180

Sánchez E, Domínguez M, Romera R, López de la Franca N, Gaertner MA, Gallardo C, Castro M (2011) Regional modeling of dry spells over the Iberian Peninsula for present climate and climate change conditions. Clim Change 107:625-634

Schär C, Vidale PL, Lüthi D, Frei C, Häberli C, Liniger MA, Appenzeller C (2004) The role of increasing temperature variability in European summer heatwaves. Nature 427: 332-336

Sillmann J, Roeckner E (2008) Indices for extreme events in projections of anthropogenic climate change. Clim Change 86:83-104

Skamarock WC, Klemp JB, Dudhia J, Gill DO and others (2008) A description of the advanced research WRF version 3. NCAR TN 475, www.mmm.ucar.edu/wrf/users/ docs/arw_v3.pdf

Sundqvist H (1978) A parameterization scheme for non-convective condensation including prediction of cloud water content. QJR Meteorol Soc 104:677-690

Editorial responsibility: Filippo Giorgi, Trieste, Italy
Tiedtke M (1989) A comprehensive mass flux scheme for cumulus parameterization in large scale models. Mon Weather Rev 117:1779-1800

- Uppala SM, Kallberg PW, Simmons AJ, Andrae U and others (2005) The ERA-40 re-analysis. QJR Meteorol Soc 131: 2961-3012

Verdin KL, Greenlee SK (1996) Development of continental scale digital elevation models and extraction of hydrographic features. Proc 3rd Int Conf/Workshop on Integrating GIS and Environmental Modeling, Santa Fe, NM, January 21-26, 1996. National Center for Geographic Information and Analysis, Santa Barbara, CA

> Vicente-Serrano SM (2006a) Differences in spatial patterns of drought on different time scales: an analysis of the Iberian Peninsula. Water Resour Manage 20:37-60

Vicente-Serrano SM (2006b) Spatial and temporal analysis of droughts in the Iberian Peninsula (1910-2000). Hydrol Sci J 51:83-97

Vicente-Serrano SM, Lasanta T, Romo A (2004) Analysis of spatial and temporal evolution of vegetation cover in the Spanish central Pyrenees: role of human management. Environ Manag 34:802-818

> Vincent LA, Mekis E (2006) Changes in daily and extreme temperature and precipitation indices for Canada over the Twentieth Century. Atmos-Ocean 44:177-193

Submitted: July 11, 2011; Accepted: August 8, 2013 Proofs received from author(s): November 26, 2013 